\title{
ÚNG DỤNG VIỄN THÁM TRONG VIỆC XÁC ĐỊNH HƯỚNG SÓNG VÀ CHIỀU CAO SÓNG VÙNG BIỂN KHU VỰC DUYÊN HẢI BẮC Bộ
}

\author{
NGUYẼ̃N HÀ PHÚ, TRẦ TUẤN NGỌC, \\ NGUYẼ̃N TH! PHƯO'NG HOA, NÔNG TH!̣ OANH
}

Cục Viễn thám Quốc gia

\section{Tóm tắt:}

Hương sóng và chiều cao sóng là một trong nhũng tham số quan trọng của sóng biển thuờng được xác định nhằm nghiên cứu các quá trình của đại duơng cũng nhu trong việc phục vu quản lý tổng hợp vùng bò̀ nhu thiết lập hành lang bảo vệ bờ biển. Nghiên cứu này, trong khuôn khổ của đề tài "Úng dụng công nghệ viễn thám và GIS trong quản lý, bảo vệ và sủ dụng hơp lý hành lang bò̀ biển Bắc bộ, thi điểm tại tỉnh Nam Định”, dũ liệu ảnh vệ tinh quang học Sentinel-2 và dũ liệu đo cao vệ tinh Jason-3 sẽ được sư dụng tương ứng để xác định hướng sóng và chiều cao sóng khu vực duyên hải Bắc Bộ. Kết quả cho thấy huớng sóng và chiều cao sóng được xác định theo phương pháp nói trên có sự tưong đồng lớn so với dũ liệu thủy văn biển.

\section{Giới thiệu}

Sóng biển là một trong các quá trình tự nhiên có vai trò quan trọng nhất đối với vùng bờ biển. Việc xác định các tham số của sóng biển như: hướng sóng, chiều cao sóng, độ dài sóng và tốc độ sóng là vô cùng cần thiết đối với sự nhận thức của con người về quá trình hình thành đường bờ biển và là cơ sở để phục vụ cho việc quản lý tổng hợp vùng bờ biển được tốt hơn.

Hiện nay, trên vùng biển khu vực duyên hải Bắc Bộ, một khu vực kinh tế trọng điểm của vùng đồng bằng Sông Hồng và vùng Đông Bắc của nước ta, trải dài qua 5 tỉnh thành bao gồm: Quảng Ninh, Thái Bình, Nam Định, Ninh Bình và $T P$. Hải phòng với diện tích phần đất liền khoảng $12,381 \mathrm{~km}^{2}$ và đường bờ biển dài $423 \mathrm{~km}$ trong phạm vi từ $19^{\circ} 55^{\prime}$ đến $21^{\circ} 40^{\prime}$ vĩ độ Bắc, việc đo đạc các tham số của sóng biển được thực hiện theo phương pháp truyền thống tại một số trạm quan trắc hoặc các trạm radar bờ biển tại những vị trí nhất định nên dẫn đến sự nhận thức về các điều kiện sóng gần bờ vốn có tính động cao bị khái quát hóa và không ghi nhận được các sóng ven biển phức tạp hơn. Gần đây, việc ứng dụng các mô hình số trị dự đoán sóng đã mang lại hiệu quả, dẫn đến sự gia tăng độ tin cậy của các dự báo sóng trên đại dương. Tuy nhiên, các mô hình này cũng có những hạn chế do không có sẵn các trị đo phổ sóng sử dụng để thẩm định trong việc tham số hóa mô hình. Cụ thể, các sóng chu kỳ dài không liên quan đến gió cục bộ được dự đoán rất kém. Ngoài ra, để thẩm định kết quả mô hình thì cũng yêu cầu cần phải có số liệu đo thực địa.

Sự phát triển các kỹ thuật viễn thám rất có tiềm năng trong việc khắc phục được các nhược điểm của những phương pháp nêu trên. Ví dụ như phép đo tán xạ để đo gió bề mặt hoặc đo cao vệ tinh để xác định độ cao mực nước biển và chiều cao sóng ngoài khơi là các kỹ thuật đã chứng minh được hiệu quả và đã đang được đưa vào ứng dụng. Bên cạnh đó, ảnh quang học máy bay hay các trị đo SAR cũng có thể giúp chiết tách các thông tin phổ sóng.

Trong các nghiên cứu gần đây, việc xác định hướng sóng và chiều cao sóng chủ yếu tập trung vào việc sử dụng dữ liệu ảnh SAR được chụp ở chế độ "Wave Mode" có độ phân giải không gian 
cao cho phép xác định hướng sóng biển có độ dài sóng ngắn và trung bình. Chương trình Copernics cho phép cung cấp miễn phí ảnh SAR Sentinel-1 đến người dùng, tuy nhiên dữ liệu ảnh ở chế độ "Wave Mode" khá hạn chế và chỉ được cung cấp cho một số vùng biển quan trọng, nên trong nội dung của bài nghiên cứu này, nhóm nghiên cứu sẽ giới thiệu một giải pháp thay thế với việc ứng dụng đo cao vệ tinh để xác định chiều cao sóng và viễn thám cận hồng ngoại NIR đê xác định hướng sóng đối với vùng biển khu vực duyên hải Bắc Bộ nước ta.

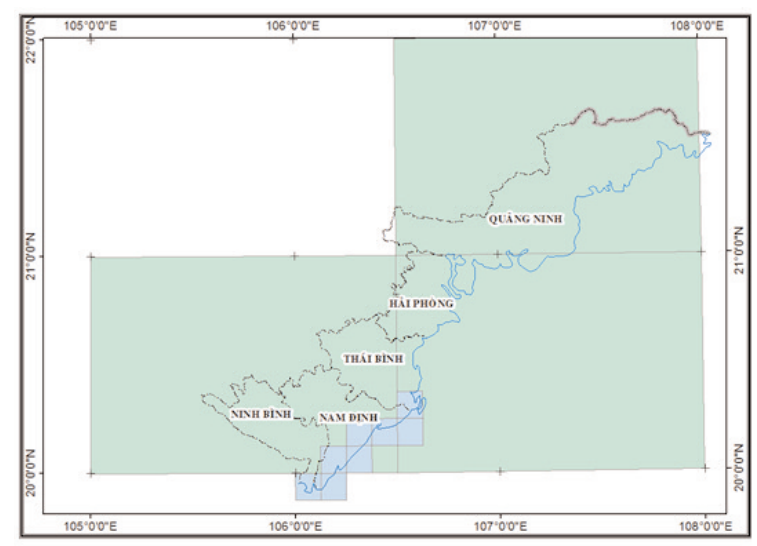

Hình 1: Vùng biển khu vục duyên hải Bắc Bộ, Việt Nam

\section{Dữ liệu sử dụng}

\subsection{Dũ liệu đo cao vệ tinh}

Dữ liệu đo cao vệ tinh được sử dụng trong phần thực nghiệm xác định chiều cao sóng là dữ liệu vệ tinh Jason-3 được thu nhận và xử lý tại Trung tâm dữ liệu WAVE-TAC (Thematic Assembly Center). Đối với khu vực thử nghiệm thuộc vùng biển ven bờ vịnh Bắc Bộ, Dữ liệu vệ tinh Jason-3 với vệt quỹ đạo 001 sẽ được thu thập trong khoảng thời gian từ tháng 04/2019 đến tháng 09/2019.

\subsection{Anh vê tinh quang hoc}

Ảnh vệ tinh quang học được sử dụng trong phần thực nghiệm này để xác định hướng sóng là ảnh Sentinel-2A có độ phân giải không gian là $10(\mathrm{~m})$. Kênh ảnh được sử dụng để tính toán hướng sóng là kênh cận hồng ngoại NIR (kênh
8). Ảnh được chụp vào ngày 07 tháng 12 năm 2019.

\section{Quy trình thực hiện}

\subsection{Xác định chiều cao sóng}

Quy trình tổng quát xác định chiều cao sóng từ dữ liệu đo cao vệ tinh được trình bày như sơ đồ dưới đây với các bước thực hiện như sau:

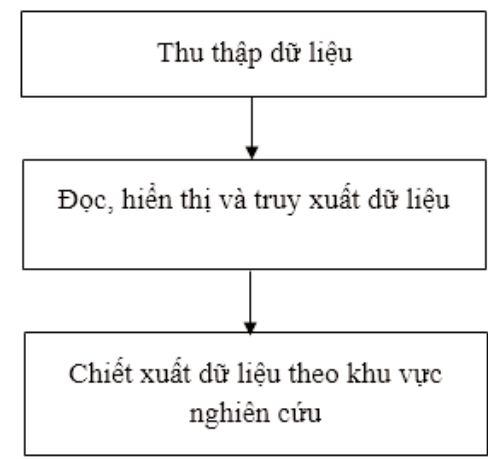

Hình 2: Quy trình công nghệ xác định chiều cao sóng

a) Thu thập dữ liệu

Dữ liệu chiều cao sóng từ đo cao vệ tinh được cung cấp bởi dịch vụ CMES (Copernicus Marine Environment Monitoring Service) tới người sử dụng thông qua trang web tại địa chỉ http://marine.copernicus.eu/servicesportfolio/access-to-products/. Dũ liệu chiều cao sóng từ đo cao vệ tinh thuộc gói dữ liệu WAVE_GLO_WAV_L3_SWH_NRT_OBSERVATIONS_014_001 là dữ liệu dọc theo quỹ đạo vệ tinh (along-track) được xử lý cận thời gian thực ở mức 3 sau mỗi khoảng thời gian là 3 (giờ). Đây là dữ liệu có độ che phủ toàn cầu được cung cấp dưới định dạng file netCDF.

b) Đọc, hiển thị và truy xuất dữ liệu

Dữ liệu chiều cao sóng từ đo cao vệ tinh chỉ có thể đọc được từ các phần mềm được phát triển có khả năng đọc được file định dạng netCDF. Trong phần này chúng tôi sử dụng phần mềm Panoply được phát triển bởi Viện nghiên cứu vũ trụ Goddard của NASA. Thông thường các phần mềm như vậy có thể hỗ trợ người dùng thực hiện các chức năng như: đọc, hiển thị và truy xuất dữ 
liệu. Theo đó, người dùng có thể xác định được tệp dữ liệu tại thời điểm vệ tinh đi qua khu vực nghiên cứu và có thể truy xuất dữ liệu dưới dạng các file *.txt thông thường để có thể dễ dàng xử lý và tính toán. Dữ liệu chiều cao sóng thường được hiển thị với các trường thông tin bao gồm: Vĩ độ (Latitude), Kinh độ (Longitude), Thời gian thu nhận (Time) và chiều cao sóng (VAVH).

c) Chiết xuất dữ liệu theo khu vực nghiên cứu

Thông thường, các trường dữ liệu như Latitude, Longitude và VAVH được truy xuất trong bước xử lý phía trên một cách riêng lẻ theo trường thuộc tính thời gian. Do đó, đối với nhiều ứng dụng thông tin địa lý, chúng ta có thể sử dụng các phần mềm tiện ích xử lý văn bản để biên tập các file dữ liệu riêng lẻ nói trên thành một file dữ liệu chung chứa đầy đủ các trường dữ liệu nói trên.

Dữ liệu chiều cao sóng từ đo cao vệ tinh sau đó sẽ được chiết xuất cho khu vực nghiên cứu theo phạm vi tọa độ địa lý kinh độ và vĩ độ. Dũ liệu này sau đó có thể sử dụng để hiển thị trên các bản vẽ hoặc được sử dụng để phân tích, tính toán phục vụ cho các ứng dụng có liên quan khác.

\subsection{Xác định hương sóng}

Quy trình tổng quát xác định hướng sóng từ ảnh vệ tinh quang học với kênh ảnh cận hồng ngoại NIR (Near Infra-red) được trình bày như sơ đồ dưới đây với các bước thực hiện như sau:

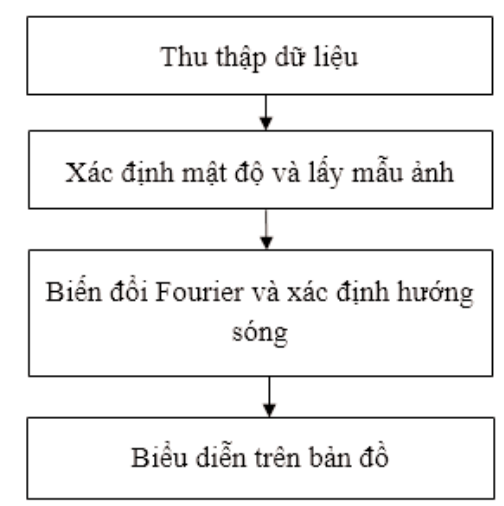

Hình 3: Quy trình công nghệxác định huớng sóng a) Thu thập dữ liệu

Dữ liệu được thu thập để xác định hướng sóng là kênh ảnh cận hồng ngoại NIR có chứa các thông tin về trạng thái bề mặt biển. Trong nghên cứu này, dữ liệu được sử dụng sẽ là ảnh Sentinel-2 được cung cấp miễn phí tại trang web dữ liệu Copernicus Open Access Hub tại địa chỉ https://scihub.copernicus.eu/dhus/\#/home.

b) Xác định mật độ và lấy mẫu ảnh

Ảnh đa phổ Sentinel-2 sau khi tải về được chuyển đổi hệ quy chiếu từ hệ tọa độ, hệ quy chiếu WGS-84 sang hệ tọa độ, hệ quy chiếu quốc gia VN2000. Ảnh Sentinel-2 sau đó sẽ được sử dụng để cắt các ảnh nhỏ được phân bố cách đều nhau. Quá trình này được gọi là lấy mẫu ảnh. Đối với khu vực ben biển Bắc Bộ, dữ liệu ảnh vệ tinh quang học sẽ được lấy mẫu theo mật độ là 10 x $10(\mathrm{~km})$. Tọa độ các vị trí lấy mẫu ảnh cũng được xác định theo hệ tọa độ bản đồ để tiện cho việc lấy mẫu. Tại mỗi vị trí lấy mẫu ảnh, việc lấy mẫu sẽ được thực hiện bằng cách cắt các ảnh nhỏ từ ảnh gốc cận hồng ngoại NIR với kích thước bằng $128 \times 128$ pixel.

c) Biến đổi Fourier và xác định hướng sóng

Các ảnh nhỏ sau khi cắt trong bước xử lý trước sẽ được biến đổi trực tiếp Fourier bằng phần mềm xử lý ảnh ENVI. Kết quả sau khi thực hiện phép biến đổi Fourier được minh họa như trong hình 4. Trên ảnh biến đổi thể hiện rõ sự phân bố hai đỉnh sóng, cho phép người dùng dễ dàng xác định được hướng sóng. Các mẫu ảnh nhỏ sau khi được biến đổi Fourier sang miền tần số sẽ được dùng để xác định các đỉnh sóng và qua đó xác định hướng sóng [1]. (Xem hình 4)

Khi đó, đỉnh sóng được xác định tọa độ trên ảnh biến đổi Fourier để tính toán hướng sóng theo công thức sau:

$$
\text { Hướngsóng }=\arctan \left(\frac{k_{y}}{k_{x}}\right)
$$

Trong đó: $\mathrm{k}_{\mathrm{x}}$ và $\mathrm{k}_{\mathrm{y}}$ là tần số không gian của sóng (tức là số lượng sóng trên một chiều dài xác định) theo trục $\mathrm{x}$ và $\mathrm{y}$ được tính theo đơn vị 
$\mathrm{rad} / \mathrm{m}$

\section{d) Biểu diễn trên bản đồ}

Hướng sóng cùng với vị trí tọa độ đã xác định sẽ được biểu diễn trên bản đồ. Loại bản đồ được sử dụng làm nền này có thể là bản đồ địa hình, bản đồ địa hình đáy biển hoặc hải đồ và bản đồ chuyên đề khác.

\section{Kết quả}

\subsection{Chiều cao sóng}

Vùng biển khu vực Duyên hải Bắc bộ chịu ảnh hưởng của chế độ nhật triều. Trong dó, vùng biển Quảng Ninh thuộc loại nhật triều đều, mỗi ngày lên xuống một lần, có độ lớn thủy triều lớn nhất Việt Nam (Mũi Chùa). Trong điều kiện bình thường, biên độ thủy triều có xu hướng giảm dần độ lớn theo hường từ Quảng Ninh xuống Hải Phòng rồi đến Thái Bình, Nam Định và Minh Bình cũng như theo hướng từ ven bờ ra ngoài khơi.

Dữ liệu chiều cao sóng thu nhận được bằng đo cao vệ tinh trên vùng biển vịnh Bắc Bộ được mô tả như trong hình 4 . Trên cơ sở phân tích dũ liệu chiều cao sóng từ đo cao vệ tinh kết hợp với bản tin thời tiết biển ven vịnh Bắc Bộ, kết quả cho thấy chiều cao sóng tại khu vực ven biển vịnh Bắc Bộ trong những điều kiện thời tiết bình thường có độ cao trung bình dưới $1,0(\mathrm{~m})$ và lớn nhất là $1,3(\mathrm{~m})$ với sức gió trung bình cấp $3-4$ (ngày 22/05/2019). Với những trường hợp như thời điểm ngày 22/04/2019, với điều kiện thời tiết biển có mưa rào và giông với sức gió mạnh cấp 4 - 5, chiều cao sóng lớn nhất được ghi nhận ở mức $1,7(\mathrm{~m})$. Trong khi đó, trong điều kiện biển động nhẹ, sức gió mạnh cấp 5 , có lúc cấp 6 , giật cấp 7 như thời điểm ngày 21/06/2019, chiều cao sóng lớn nhất đạt đến mức 1,8 (m) [2]. (Xem hinh 5)

Trong điều kiện thời tiết không bình thường, biển động mạnh như thời điểm ngày 29/08/2019, tại khu vực ven biển Vịnh Bắc Bộ do chịu ảnh hưởng của cơn bão số 4 với sức gió mạnh cấp 7 - 8 , chiều cao sóng lớn nhất ở mức từ $2,0(\mathrm{~m})$ đến hơn 3,2 (m) với chiều cao sóng cao hơn ở khu vực vùng biển Nam Định và thấp dần theo hướng tới vùng biển Quảng Ninh.

\subsection{Hướng sóng}

Kết quả thành lập bản đồ hướng sóng cho thấy tồn tại một số trường hợp điển hình đối với phổ ảnh của sóng được mô tả như trong Hình 6 dưới đây. Đối với vùng biển xa bờ (Hình 6.a) có chiều dài sóng lớn hơn thì bản đồ phổ ảnh thể hiện rõ ràng với hai đỉnh sóng cho phép xác định hướng sóng một cách chính xác. Tuy nhiên, việc xác định hướng sóng theo hai đỉnh cũng cần phải kêt hợp với hướng gió được xác định theo phương pháp mô hình hoặc sử dụng kiến thức chuyên gia có sự hiểu biết về sự thay đổi hướng gió theo mùa hàng năm để xác định hướng sóng một cách chính xác. (Xem hình 6)

Một số khu vực gần về phía bờ (Hình 6.c) sóng có chiều dài rất nhỏ, độ cao sóng thấp cùng với sự di chuyển nhanh, không ổn định nên khi đó biểu đồ phổ ảnh cũng không rõ ràng hơn và

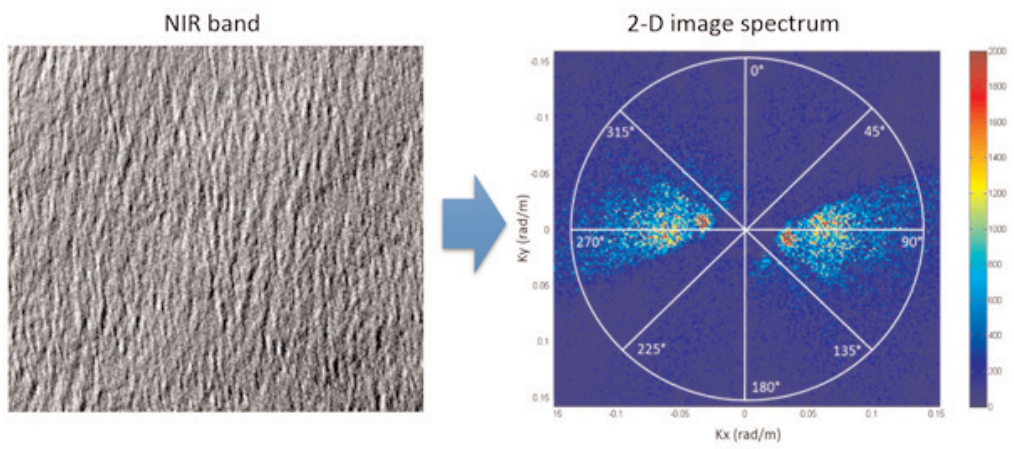

Hình 4: Biến đổi Fourier tù ảnh cận hồng ngoại 
nhiễu với cấu trúc nhận dạng không nhận biết được. Trong khi đó, theo hướng càng sát đến gần ven bờ biển (Hình 6.b), biểu đồ phổ ảnh thường lại cho kết quả kém rõ ràng và đôi khi ở các mẫu ảnh ta có thể thấy các trường hợp nhiều hơn hai đỉnh đối xứng qua tâm do sóng biển lúc này có chiều dài bước sóng ngắn, và chịu ảnh hưởng của các yếu tố như địa hình khu vực thềm đáy biển và các dòng thủy triều.

Kết quả xác định hướng sóng bằng ảnh vệ tinh quang học Sentinel-2 được biểu diễn như trong Hình 7 dưới đây. Việc so sánh với các số liệu về sóng của Trung tâm Dự báo khí tượng thủy văn quốc gia [3] cho thấy có sự tương đồng giữa kết quả xác định hướng sóng bằng ảnh vệ tinh quang học Sentinel-2 với bản đồ hướng sóng được công bố trên Website của Trung tâm. (Xem hìn 7)

Kết quả cũng cho thấy rằng độ phân giải của ảnh cũng là yếu tố quan trọng trong việc xác định hướng sóng. Đối với ảnh Sentinel-2, việc xác định hướng sóng của các con sóng có chiều dài hơn $100 \mathrm{~m}$ có thể thực hiện được nhưng đối với các con sóng gần bờ có chiều dài sóng chỉ vài chục $\mathrm{m}$ thì độ phân giải yêu cầu của ảnh cần phải lớn hơn.

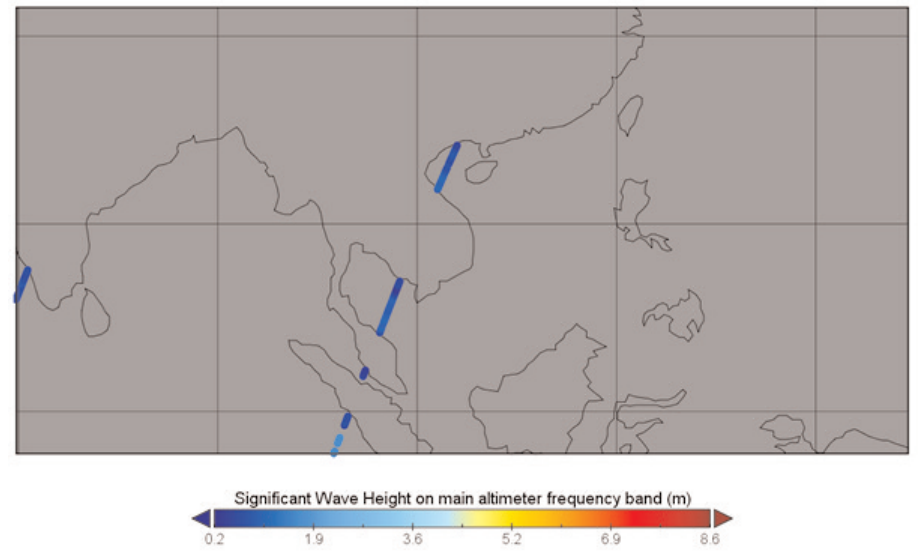

Hình 5: Quỹ đạo vệ tinh Jason-3 001 đi qua vùng ven biển vịnh Bắc Bộ
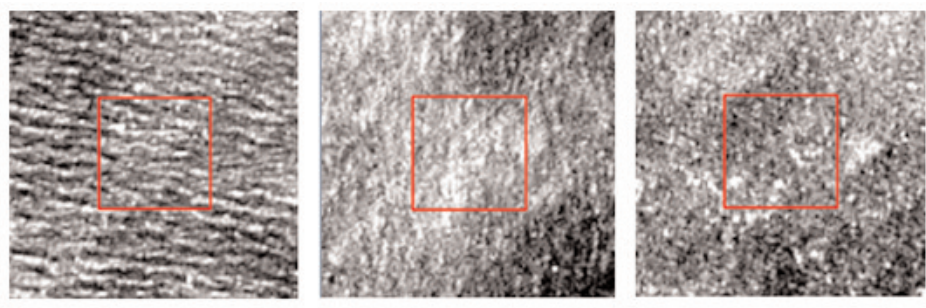

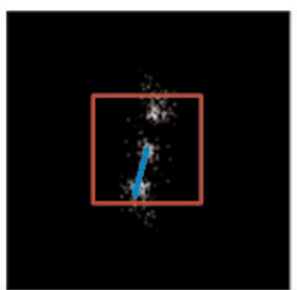

(a)

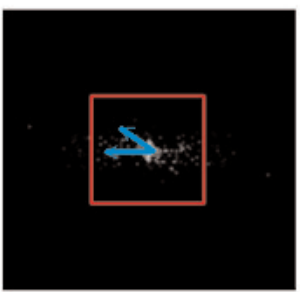

(b)

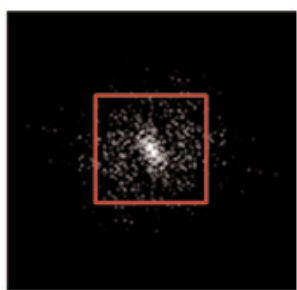

(c)

Hình 6: Một số mẫu sóng tiêu biểu. Hình phía trên là ảnh cận hồng ngoại, hình phía dưới là phổ ảnh. 


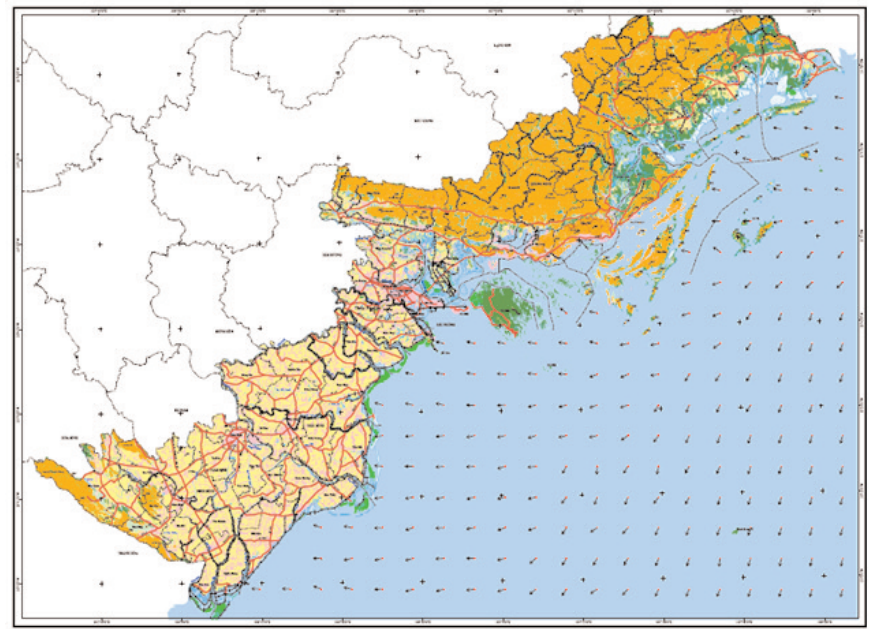

Hình 7: Bản đồ hướng sóng vùng biển khu vực duyên hải Bắc Bộ

\section{Kết luận}

Việc kết hợp ảnh viễn thám quang học với đo cao vệ tinh đã chứng tỏ được tính hiệu quả trong việc xác định hướng sóng và chiều cao sóng phục vụ cho công tác quản lý vùng bờ biển. Đối với khu vực vùng biển duyên hải Bắc Bộ, việc bổ xung thêm các nguồn số liệu hướng sóng và chiều cao sóng ngoài khơi thay vì chỉ có số liệu ven bờ được cung cấp từ các trạm quan trắc sẽ giúp tăng cường khả năng độ chính xác, độ tin cậy của các mô hình và giúp cho công tác dự báo thủy văn biển được tốt hơn. $\bigcirc$

\section{Tài liệu tham khảo}

[1]. Jonhson, M., Luck-Vogel, M. 2017, Extraction of coastal ocean wave characteristics using remote sensing and computer vision technologies, ISRSE37, Pretoria, 8-12 May, 2017.

[2]. Đài khí tượng thủy văn tỉnh Thái Bình, Dự báo thời tiết biển $24 \mathrm{~h}$, truy cập ngày 18 tháng 10 năm 2019, http://kttv.thaibinh.gov.vn/TinTuc/Du_bao_thoi_tiet_bien_24_gio.

[3]. Tổng Cục Khí tượng thủy văn, Trung tâm Dự báo khí tượng thủy văn quốc gia, Dự báo Sóng, truy cập ngày 18 tháng 10 năm 2019, http://nchmf.gov/Kttvsite/vi-VN/1/Song-2515.html. $\bigcirc$

\section{Summary}

The application of remote sensing in determining ocean wave direction and significant wave height in the Northern coastal region of Vietnam

Nguyen Ha Phu, Tran Tuan Ngoc, Nguyen Thi Phuong Hoa,

\section{National Remote Sensing Department}

\section{Nong Thi Oanh, The Hanoi University of Geodegy and Mining}

Ocean wave direction and significant wave height are one of the most important parameters of ocean waves that are often determined to study ocean processes as well as to serve the coastal integrated management such as the establishment of a coastal protection corridor. In this study, Sentinel2 optical satellite image data and Jason-3 satellite altimetry data will be used respectively to determine wave direction and significant wave height in the Northern coastal region of Vietnam. The results show that wave direction and significant wave height determined by the above method have a great similarity with the sea hydrographic data. $\bigcirc$ 